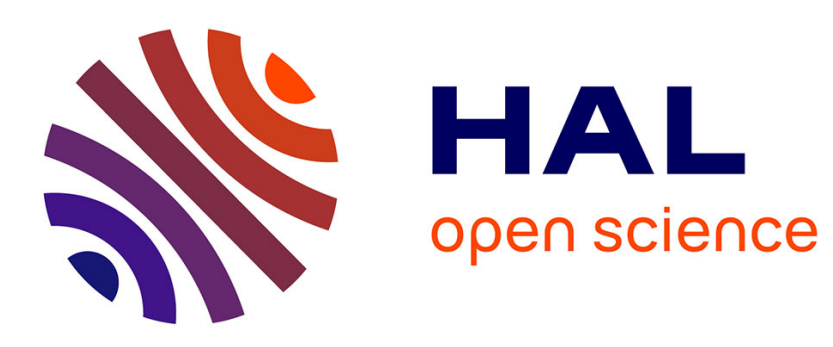

\title{
Stochastic Modeling of Soft Magnetic Properties of Electrical Steels: Application to Stators of Electrical Machines
}

\author{
Rindra Ramarotafika, Abdelkader Benabou, Stéphane Clenet
}

\section{To cite this version:}

Rindra Ramarotafika, Abdelkader Benabou, Stéphane Clenet. Stochastic Modeling of Soft Magnetic Properties of Electrical Steels: Application to Stators of Electrical Machines. IEEE Transactions on Magnetics, 2012, 48 (10), pp.2573 - 2584. 10.1109/TMAG.2012.2201734 • hal-00824528

\section{HAL Id: hal-00824528 \\ https://hal.science/hal-00824528}

Submitted on 22 May 2013

HAL is a multi-disciplinary open access archive for the deposit and dissemination of scientific research documents, whether they are published or not. The documents may come from teaching and research institutions in France or abroad, or from public or private research centers.
L'archive ouverte pluridisciplinaire HAL, est destinée au dépôt et à la diffusion de documents scientifiques de niveau recherche, publiés ou non, émanant des établissements d'enseignement et de recherche français ou étrangers, des laboratoires publics ou privés. 


\title{
Stochastic Modeling of Soft Magnetic Properties of Electrical Steels: Application to Stators of Electrical Machines
}

\author{
R.Ramarotafika ${ }^{1,2}$, A.Benabou ${ }^{2}$, S.Clénet ${ }^{1}$ \\ ${ }^{1}$ L2EP/Arts et Métiers ParisTech, Centre de Lille, 8 boulevard Louis XIV - 59046 Lille Cedex, France \\ ${ }^{2}$ L2EP/Université Lille1, Bâtiment P2, Cité Scientifique - 59655 Villeneuve d'Ascq, France
}

To take account of the uncertainties introduced on the soft magnetic materials properties (magnetic behavior law, iron losses) during the manufacturing process, the present work deals with the stochastic modeling of the magnetic behavior law B-H and iron losses of claw pole stator generator. Twenty eight (28) samples of slinky stator (SS) coming from the same production chain have been investigated. The used approaches are similar to those used in mechanics. The accuracy of existing anhysteretic models has been tested first using cross validation techniques. The well known iron loss separation model has been implemented to take into account the variability of the losses. Then, the Multivariate Gaussian distribution is chosen to model the variability and dependencies between identified parameters, for both behavior law and iron loss models. The developed stochastic models allow predicting a $98 \%$ confidence interval for the considered samples.

Index Terms - slinky stator, magnetic behavior law, iron losses, variability, stochastic model

\section{INTRODUCTION}

$\mathrm{F}^{\mathrm{o}}$ OR optimal design of electrical machines, the knowledge of magnetic steel properties, such as the magnetic behavior law and iron losses is of importance, especially in the context of more and more constraining requirements for energy efficiency. In order to improve the accuracy of electrical devices modeling, many works have been concerned with the modeling of iron losses [1-3] and magnetic behavior law [4]. These models are found to be acceptable, when the input parameters, related to the geometry and physical properties, are assumed to be well known. However, such assumption reveals itself insufficient as the manufacturing of an electrical machine, from the cutting of laminations till the final magnetic core shape, requires several industrial processes that might significantly impact the magnetic properties. In fact, these processes may introduce some residual stresses that have an impact on the magnetic behavior law and iron losses of the considered material [30-33]. Therefore, the magnetic properties of the magnetic steel, before and after the implementation of these different processes, are generally modified, locally or globally. Moreover, the impact of these processes is not necessarily uniform and can lead to a significant variability in the magnetic characteristics. Most of the works investigate only the relationships between the magnetic properties and mechanical stresses and do not emphasize the variabilities that can be introduced. The work presented in [5], reported that the vector magnetic property of the electrical steel sheet depends on the mechanical stress and the direction of the magnetic field excitation and has to be taken into account when designing the electrical machine. Moreover, the work in [6] describes a method for detecting stress on the surface of magnetic materials, such as steels, using measurements of magnetic Barkhausen emissions. These results are interesting as they put in evidence the impact of mechanical stress on the local magnetic properties.

Nevertheless, the mechanical stress induced by the manufacturing process, is not necessarily well known and not the same for all samples issued from the production chain. This is due, for example, to the cutting tool wear. Therefore, it is of interest to have a stochastic approach in order to take into account the uncertainties introduced by the manufacturing on the magnetic behavior law and iron losses. In fact, stochastic models became in the last decade a great challenge, and are particularly used in various fields such as civil and mechanical engineering. Generally speaking, it aims to investigate uncertainties on input parameters of a model, and then to study their impact on the model output(s) [8-14]. The proposed common scheme for dealing with uncertainties using a stochastic model relies upon three steps, namely the definition of the mathematical model of the physical system, the probabilistic characterization and modeling of the uncertainties on the model parameters and the propagation of these uncertainties through the model [11].

The present work is focused on the second step, consisting in modeling the uncertainties of the magnetic behavior law and iron losses. Then, the model that is constructed is applied to describe the magnetic properties of the yoke for twenty eight slinky stator samples (SS) used in claw-pole alternators. Studying this kind of stator is of interest as the manufacturing process, consisting in a long strip of steel lamination that is progressively punched and rolled up in a spiral way, may have noticeable impact and variability. Note that the modeling approach is similar to those presented in the field of fatigue crack growth in mechanical probabilistic modeling, which are mainly interested in modeling the stochastic aspect of the fatigue of material, through Paris Erdogan model [12].

The first part of this paper concerns the variability aspect of the magnetic behavior law and iron losses, quantified on the aforementioned slinky stator samples. The main objective is to explain the outline of the experimental approach and the obtained results, as further details can be consulted in [15]. Development of stochastic model would be then based on these experimental data.

The second part of this paper is related to the development of a stochastic model for the magnetic behavior law. The 
approach for simulating the inverse model $\mathrm{H}(\mathrm{B})$ will be also presented. In fact, an inverse model is required for vector potential formulation when modeling a device, for example, using the finite elements method. Finally, the third part concerns the stochastic modeling of iron losses at $50 \mathrm{~Hz}$, although the stochastic model can be extended for other levels of frequency.

\section{EXPERIMENTATION ON SLINKY STATOR SAMPLES}

\section{A. Experimental protocol}

Twenty eight slinky stator (SS) samples made from standard grade laminations M800-50A, with the same geometrical dimension and coming from a production chain of claw pole generator are investigated. The core manufacturing process of slinky stators is based on a long strip of steel lamination that is progressively punched and rolled up in a spiral way. Stators obtained from this way of manufacturing are known as "slinky stators". This method is used to reduce the material waste. It requires special manufacturing techniques and production machines. The rolling process might then negatively influence the magnetic properties of the material, especially the iron losses that increase [7].

The main purpose of the experiment is to quantify the variability of the magnetic behavior law B-H and iron losses $\left(\mathrm{P}_{\mathrm{s}}\right)$ of the stator sample's yokes. To this end, primary and secondary windings have been realized along their yoke, as for the magnetic characterization of a toroidal sample: each stator sample has an excitation winding that creates a magnetic flux in the yoke along its perimeter, and a secondary winding is added to measure the magnetic flux density (figure1).
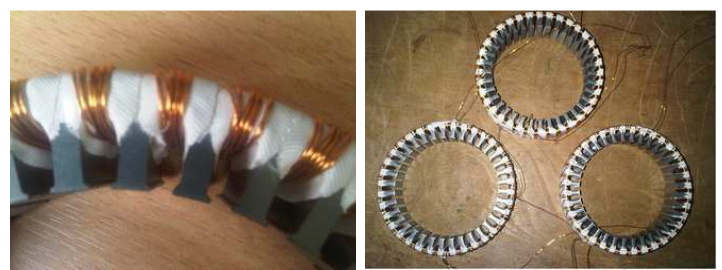

Fig. 1.Samples of stators

The experimental characterization is carried out under sinusoidal magnetic flux density, for different levels of excitation field $\mathrm{H}_{\max }$ and at $50 \mathrm{~Hz}$.

The quantities of interest are the iron losses $P_{s}$ and the maximum magnetic flux density $B_{\max }$. Their variabilities are quantified using descriptive statistics and by calculating the empirical Coefficient of Variation $(\mathrm{Cv})$, which is the ratio of the standard deviation $\sigma$ to the mean $\mu$.

$$
C v=\frac{\sigma}{\mu}
$$

In order to verify that uncertainties are mainly related to the magnetic properties, influences of the noise measurements, manual windings and geometrical tolerances have been investigated [15]. Results showed that, for a given stator sample, the potential sources of uncertainties are not significant. Therefore, if a significant variability is identified among the stators samples, this one can be linked directly to the degradation of the magnetic properties due to manufacturing processes.

\section{B. Magnetic behavior law and iron losses variability}

In figure 2, the behavior law $\mathrm{B}_{\max }\left(\mathrm{H}_{\max }\right)$, for $50 \mathrm{~Hz}$, is given for all samples. The variability of $\mathrm{B}_{\max }$ for the considered $\mathrm{H}_{\max }$ interval is between $2 \%$ and $1 \%$ (from lower to higher $\mathrm{H}_{\max }$ level).

At the opposite, numerical models of electrical devices can require the use of the inverse behavior law, i.e. with the magnetic flux density $\mathrm{B}$ as input variable. This is the case of the standard vector potential formulation in 2D finite element analysis for example. Then, from the experimental $\mathrm{B}_{\max }\left(\mathrm{H}_{\max }\right)$ curves, the inverse $\mathrm{H}_{\max }\left(\mathrm{B}_{\max }\right)$ curves are deduced by interpolating between experimental points for given $B_{\max }$ values. Therefore, the identification of the variability of $H_{\max }$, when fixing the magnetic flux density $\mathrm{B}_{\max }$, becomes much higher as the $\mathrm{B}_{\max }$ level increases, and varies from $3.72 \%$ to $5.77 \%$, as presented in figure 3 .

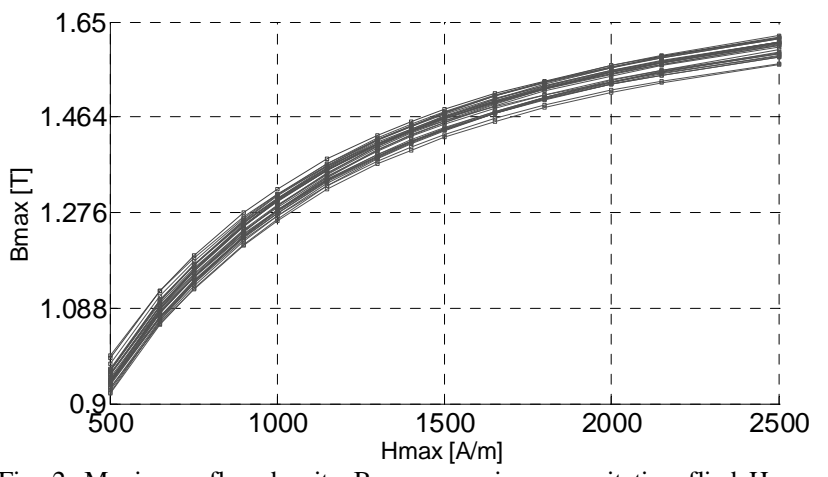

Fig. 2. Maximum flux density $B_{\max }$ vs maximum excitation flied $H_{\max }$ characteristics of $28 \mathrm{SS}$ samples

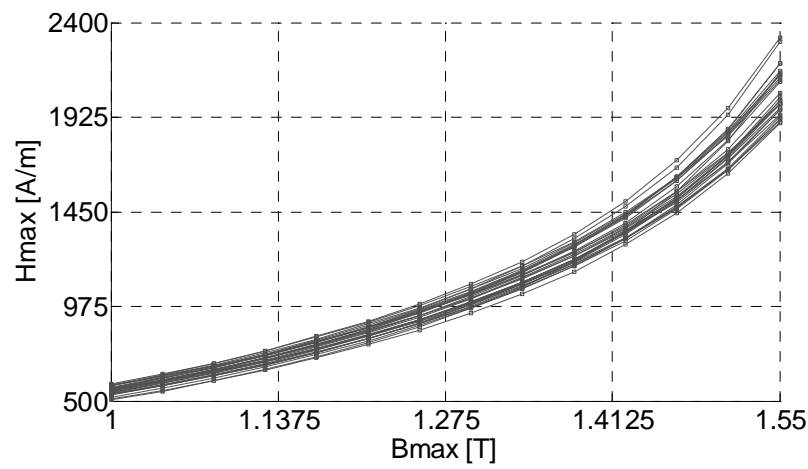

Fig. 3. Maximum excitation flied $\mathrm{H}_{\max }$ vs maximum flux density $\mathrm{B}_{\max }$ : $\mathrm{Cv}$ is much higher with increasing $B_{\max }$ level

These variabilities are introduced by the manufacturing that is constituted of several processes. The process that is most likely to introduce variability in the behavior law is the mechanical stress when the strip of steel lamination is rolled up in a spiral way. Moreover, the punching can also introduce variability among the samples along with the wear of the punching tool. By considering the samples in their final state 
after these processes, the observed variability is a global one and it can not be distinguished which one is the most preponderant. Nevertheless, for the electrical machine designer, this global variability is the one of interest.

The iron losses $\mathrm{P}_{\mathrm{s}}$ are also investigated at $50 \mathrm{~Hz}$. Their variability is about $6 \%$ for all $\mathrm{H}_{\max }$ levels (figure 4). In order to analyze this variability for both static and dynamic contributions, the loss separation technique is applied, by characterizing the whole samples for several levels of $\mathrm{B}_{\max }$ and frequencies. It is found that the $\mathrm{Cv}$ of static losses is more significant compared to the $\mathrm{Cv}$ of dynamic losses (figure 5) [15].

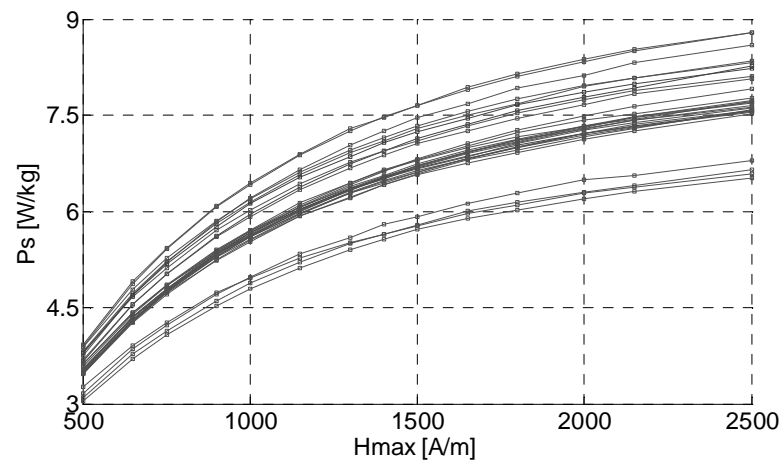

Fig. 4. Iron losses $P_{s}$ vs the maximum excitation field $H_{\max }$ for the $28 \mathrm{SS}$ samples

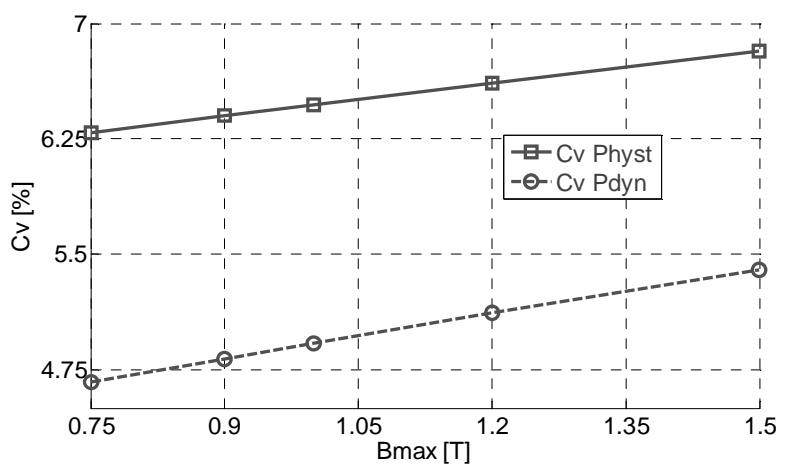

Fig. 5. Coefficient of Variation of static and dynamic components of losses of $28 \mathrm{SS}$ samples at $50 \mathrm{~Hz}$

As for the behavior law, the observed variability in iron losses is most likely the consequence of the mechanical stress introduced by the punching and the rolling up in a spiral of the strip of lamination. Moreover, the impact is mainly observed on the static losses that are directly linked to the hysteresis behavior [33]

From these experimental observations, the main objective of this paper is to develop stochastic models that will take into account the variabilities for both the magnetic behavior law and iron losses for a direct use in electrical devices design.

\section{ANHYSTERETIC CURVE MODELS AND CROSS VALIDATION TECHNIQUE}

\section{A. Literature review}

To describe the non-linear behavior law, some models are based on purely mathematical approximations, as presented in
[16]. A hyperbolic approximation is, for example, the well known Froelich's equation given by,

$$
|B|=\frac{|H|}{a+b|H|} .
$$

The coefficients $a$ and $b$ are determined from a plot of $1 /|\mathrm{B}|$ vs $1 /|\mathrm{H}|$. A transcendental function has been presented in [16] to approximate the anhysteretic curve, and is expressed by,

$$
B=\operatorname{atan}^{-1}(b H)
$$

where $a$ and $b$ are determined from experimental data. Other models are based on physical considerations, such as energy approaches, and the existence of coupling between the magnetic domains. By applying Maxwell-Boltzmann statistics and some algebraic calculations, the bulk magnetization can be approximated with the well known Langevin equation [17], which is given by,

$$
M(H)=M_{s a t}\left[\operatorname{coth}\left(\frac{H+\alpha M}{a}\right)-\frac{a}{H+\alpha M}\right]
$$

where $\mathrm{M}_{\mathrm{sat}}$ is the saturation magnetization, $\alpha$ the mean field parameter representing inter-domain coupling and $a$ is given by $a=k T / m$, where $k$ is the Boltzmann's constant, $T$ the temperature in Kelvin, and $m$ the magnetic moment per unit volume. The three parameters $\left(M_{s a}, a, \alpha\right)$ of the model are identified from the experiment.

An interesting model, presented in [18], is based on the Rayleigh model and Brillouin equation. The Rayleigh model is used for modeling minor centered loops and is given by:

$$
M(H)=\alpha H+\beta|H| H
$$

where the linear term represents the reversible component, and the quadratic term the irreversible component of magnetization. Brillouin's equation allows approximating the entire reversible anhysteretic magnetization curve and its expression is given by,

$$
\frac{M(H)}{M_{s a t}}=\frac{2 J+1}{2 J} \operatorname{coth}\left(\frac{2 J+1}{2 J} \frac{H}{a}\right)-\frac{1}{2 J} \operatorname{coth}\left(\frac{1}{2 J} \frac{H}{a}\right)
$$

where $M_{\text {sat }}$ is the saturation magnetization, $J$ the quantum number of the atom, and $a$ the shape parameter depending on the material properties and the temperature. With some assumptions on the physical phenomenon of the magnetization and combining (5) and (6), an expression for the magnetization can be deduced and given by expression (7).

$$
M(H)=M_{a} L\left(\frac{H}{a}\right)+M_{b} \tanh \left(\frac{|H|}{b}\right) L\left(\frac{H}{b}\right)
$$


where $M_{a}, M_{b}$ denote the reversible and irreversible components of saturation magnetization, and $a, b$ determine the rate of their approach to saturation. These parameters are identified again from experimental measurements.

\section{B. Coefficient of efficiency}

The coefficient of efficiency $R^{2}$ can be used to measure the accuracy of the fitting process. It takes values between 0 and 1 , and evaluates the fraction of variance in the observed data that can be explained by the model. A higher value indicates better agreement. Its expression is given by,

$$
R^{2}=1-\frac{\sum_{i=1}^{n}\left(B_{\text {meas }}\left(H_{i}\right)-B^{*}\left(H_{i}\right)\right)}{\sum_{i=1}^{n}\left(B_{\text {meas }}\left(H_{i}\right)-\overline{B_{\text {meas }}(H)}\right)} .
$$

In this relation, $n$ is the number of experimental data, $\overline{B_{\text {meas }}(H)}$ is the mean over the measured magnetic flux densities, $B_{\text {meas }}\left(H_{i}\right)$ and $B^{*}\left(H_{i}\right)$ are respectively the measured and the estimated (model) characteristics for the corresponding $H_{i}$ level. However, $R^{2}$ may be oversensitive to extreme values or outliers. An improvement over $R^{2}$ for model evaluation purposes is the adjusted coefficient of efficiency $R_{a}^{2}$ given by,

$$
R_{a}^{2}=1-\frac{n-1}{n-q-1}\left(1-R^{2}\right)
$$

where $q$ is the number of parameters of the model.

\section{Cross-Validation technique}

The coefficient of efficiency mentioned above can be applied to check the accuracy of the model for available experimental dataset. However, its drawback is that it does not allow verifying the behavior of the selected model on future as-yet-unseen data. Moreover, training an algorithm and evaluating its statistical performance on the same data yields an overoptimistic result. Assume that we have a sample of size $n$ such as $\boldsymbol{y}=\left(y_{1}, y_{2}, \ldots y_{n}\right)$ and we want to estimate a family of parameters $\boldsymbol{a}=\left(a_{1}, a_{2}, \ldots a_{m}\right)$ of the model $f(\boldsymbol{a})$ chosen to represent the data. The least square technique can then be used to find the values of the parameters, and consists in minimizing,

$$
\Gamma=\sum_{i=1}^{n}\left(y_{i}-f\left(x_{i 1}, x_{i 2}, \ldots x_{i m}, a_{1}, a_{2}, \ldots a_{m}\right)\right)^{2} .
$$

Parameters are identified by minimizing $\Gamma$, and then the function $f(\boldsymbol{a})$ is chosen to represent the phenomenon (model). Obviously, if more parameters are taken, the fitting will be better. However, the question is what will be the behavior of the model if new observations are available. In other words, assume that new observations $\left(y_{n+1}, \ldots y_{n+i}\right)$ are available, the question is now can our model predict these new observations or which functions predict better these observations? New differences can be calculated using the expression,

$$
P=\frac{1}{l} \sum_{i=1}^{l}\left(y_{n+i}-f\left(x_{(n+i) l}, \ldots x_{(n+l) m}, a_{1}, a_{2}, \ldots a_{m}\right)\right)^{2}
$$

where $P$ is the prediction error. Obviously, we can postulate that the model that gives the smallest $P$ has a higher predictive power. On the other hand, the model that gives smaller $\Gamma$ but larger $P$ corresponds to an overfitted model.

The Cross-Validation Technique (CVT) [19-22] is a suitable method to carry out such analysis. This technique is widely used in modern statistical analysis and data mining. Its main purpose is to split the available data into two subsets, by performing the analysis on one subset (training set), and validating the analysis on the other subset (testing set). It allows the attempts to reduce overfitting and thus help to the model selection. With a set of experimental data of size $n$, the principle of the method is as follow:

- divide the experimental data set into $K$ equally sized subsets (or nearly equally) or folds,

- for the $k$-th subset, estimate parameters using (11) with the $(K-1)$ subsets excluding the $k$-th subset. Calculate prediction error using (12) for the $k$-th subset,

- repeat the second step for all $k=1,2, \ldots, K$ and combine all prediction errors to get a cross-validation prediction error.

Technically, one can use a K-fold cross-validation or a leave-one-out cross-validation (in this case $K=n$ ). Let us denote an estimate of the vector of parameters at the $k$-th step by $\boldsymbol{a}_{k}$ and the number of points in this subset $N_{k}$. The prediction error of the model per observation is given by,

$$
E_{r r}=\frac{1}{K} \sum_{k=1}^{K} \frac{1}{N_{k}} \sum_{i \in A_{k}}\left(y_{i}-f\left(x, a_{k}\right)\right)^{2} .
$$

One can then choose the model that gives the smallest prediction error $E_{r}$.

\section{MAGNETIC BEHAVIOR LAW STOCHASTIC MODELING}

To develop a stochastic model for the magnetic behavior law, the following steps are performed:

- Comparison of existing anhysteretic models accuracy, using goodness of fit measures. The objective is to find the one that would present the lowest error rate.

- Identification of the parameters of the chosen model for the whole samples.

- Identification of the probabilistic model using identified parameters.

- Validation of the model using a statistical test and identification of the Confidence Interval (CI). 


\section{A. Deterministic anhysteretic model performance comparison}

The accuracy of the Froelich (3), transcendental (4), Langevin (6) and modified Brillouin (8) models is quantified. To this end, the $\mathrm{B}_{\max }\left(\mathrm{H}_{\max }\right)$ characteristic measured on an arbitrary chosen sample is investigated, and parameters are identified by minimizing (11). The corresponding coefficients of efficiency are summarized in table 1. It is shown that all identified models allow predicting fairly and accurately the experimental data points.

TABLE I

COEFFICIENT OF EFFICIENCY IDENTIFIED FOR THE 4 ANHYSTERETIC MODELS

\begin{tabular}{lcccc}
\hline \hline & $\begin{array}{c}\text { Modified } \\
\text { Brillouin }\end{array}$ & Langevin & Froelich & Transcendental \\
\hline $\mathrm{R}^{\mathbf{2}}$ & 0.990 & 0.975 & 0.989 & 0.985 \\
\hline \hline
\end{tabular}

Although the efficiency coefficient for the Langevin model is the smallest one, the difference with the others is not significant. Thereafter, considering the size of our samples, a 3-fold CVT is applied: data points are split into 3 sub-samples, respectively for $\mathrm{H}_{\max }=[500 ; 1000] \mathrm{A} / \mathrm{m}, \mathrm{H}_{\max }=[1150 ; 1500]$ $\mathrm{A} / \mathrm{m}$ and $\mathrm{H}_{\max }=[1650 ; 2500] \mathrm{A} / \mathrm{m}$. For each fold, the parameters of the model are identified from the training samples, and the error rate evaluated from the test set. The global error is then the average of the error rate for the 3 folds. This procedure is performed on the 4 models, and the error rate evaluated for each fold is presented in table 2 , and the global error rate for each model in table 3.

TABLE II

ERROR RATE FOR EACH FOLD AND EACH ANHYSTERETIC MODEL

\begin{tabular}{cccc}
\multicolumn{4}{c}{ ERROR RATE FOR EACH FOLD AND EACH ANHYSTERETIC MODEL } \\
\hline \hline & $1^{\text {st }}$ fold & $2^{\text {nd }}$ fold & $3^{\text {rd }}$ fold \\
\hline Froelich & $1.64 \times 10^{-3}$ & $2.02 \times 10^{-4}$ & $1.04 \times 10^{-3}$ \\
Modified Brillouin & $4.47 \times 10^{-6}$ & $3.34 \times 10^{-6}$ & $1.03 \times 10^{-5}$ \\
Langevin & $1.33 \times 10^{-2}$ & $1.04 \times 10^{-3}$ & $6.75 \times 10^{-3}$ \\
Transcendantal & $3.58 \times 10^{-3}$ & $2.79 \times 10^{-4}$ & $2.16 \times 10^{-3}$ \\
\hline \hline
\end{tabular}

TABLE III

GLOBAL ERROR RATE FOR EACH ANHYSTERETIC MODEL

\begin{tabular}{cc}
\hline \hline & Global Error $E_{r r}$ \\
\hline Froelich & $9.36 \times 10^{-4}$ \\
Modified Brillouin & $6.042 \times 10^{-6}$ \\
Langevin & $7.058 \times 10^{-3}$ \\
Transcendantal & $2.009 \times 10^{-3}$ \\
\hline \hline
\end{tabular}

According to these results, the modified Brillouin model presents the lowest global error compared to the other models. This justifies its use to model the behavior law of the SS.

\section{B. Parameters variability}

In order to investigate stochastic model validation later, experimental data is split into two groups: the modeling subset used to construct the stochastic model (containing modeling experimental data), and the test subsets to validate the model [23]. The set of parameters $\left(M_{a}, M_{b}, a, b\right)$ for 23 experimental trajectories (used for modeling subsets) chosen randomly, are then identified by minimizing (11). The histograms and the scatter plots of these parameters are presented in figures 6 and 7 respectively. The linear correlation matrix of these parameters is summarized in table 4 , and supposes a strong linear dependency between them.

TABLE IV

CORRELATION MATRIX OF ANHYSTERETIC MODEL PARAMETERS

\begin{tabular}{ccccc}
\hline \hline & $\mathrm{M}_{\mathrm{a}}$ & $\mathrm{M}_{\mathrm{b}}$ & $\mathrm{a}$ & $\mathrm{b}$ \\
\hline $\mathrm{M}_{\mathrm{a}}$ & 1 & $-0,98$ & $-0,66$ & $-0,82$ \\
$\mathrm{M}_{\mathrm{b}}$ & $-0,98$ & 1 & 0,75 & 0,9 \\
$\mathrm{a}$ & $-0,66$ & 0,75 & 1 & 0,79 \\
$\mathrm{~b}$ & $-0,82$ & 0,9 & 0,79 & 1 \\
\hline \hline
\end{tabular}

Therefore, the chosen probabilistic model should be able to take into account both the variability of each parameter and the correlation between the parameters. Unfortunately, it is difficult to infer a probability distribution from only 23 realizations. Therefore, we have proposed a Multivariate Gaussian (MG) distribution which is able to model both variability and dependence between these parameters. The algorithm for generating a MG distribution from experimental samples is presented in Appendix A.1.

\section{Model validation}

\section{1) Statistic goodness of fit}

Once the MG distribution is obtained, a Monte Carlo simulation is performed for one million realizations. This is achieved for each $\mathrm{H}_{\max }$ level and the corresponding $\mathrm{B}_{\max }$ empirical Cumulative Distribution Functions $\mathrm{F}(\mathrm{x})$ (CDF) are identified. In order to check the goodness of fit statistics, the identified and experimental CDF are compared, as illustrated in figure 8 for four levels of $\mathrm{H}_{\max }$. According to these figures, an experimental CDF is well approximated by the simulated one. Thereafter, a two samples Kolmogorov Smirnov (KS) (Appendix B) test is then implemented to test the null hypothesis $\mathrm{H}_{0}$ that they are issued from the same continuous distribution, at a risk of $5 \%$, against the hypothesis $\mathrm{H}_{1}$ that they are from different probability distribution. For all $\mathrm{H}_{\max }$ levels, the $\mathrm{p}$ values (if $\mathrm{p}$-value $>5 \%$, null hypothesis is not rejected) of the test are between 0.5 and 0.9 . These values then allow not rejecting the null hypothesis, for all $\mathrm{H}_{\max }$ levels at a risk of $5 \%$. This validates the simulated $\mathrm{CDF}$.

2) Confidence interval

The $98 \%$ confidence interval (CI) of $\mathrm{B}_{\max }$ is identified for all $\mathrm{H}_{\max }$ levels. Figure 9 shows that the modeling subset is within the predicted $98 \%$ CI. Moreover, the predicted and experimental medians are also very close as shown in figure 10. Indeed, the error between the predicted and experimental median is less than $1 \%$ for the whole level of $\mathrm{H}_{\max }$. Finally, test subsets are reported in figure 11 showing that they also lie within the identified CI, although they have not been used for the MG distribution generation. All these comparisons allow then to validate the MG distribution chosen for the variability of the vector of 4 parameters and make. The model can be further used as input for stochastic finite elements analysis in scalar potential formulation $[13,14]$. 

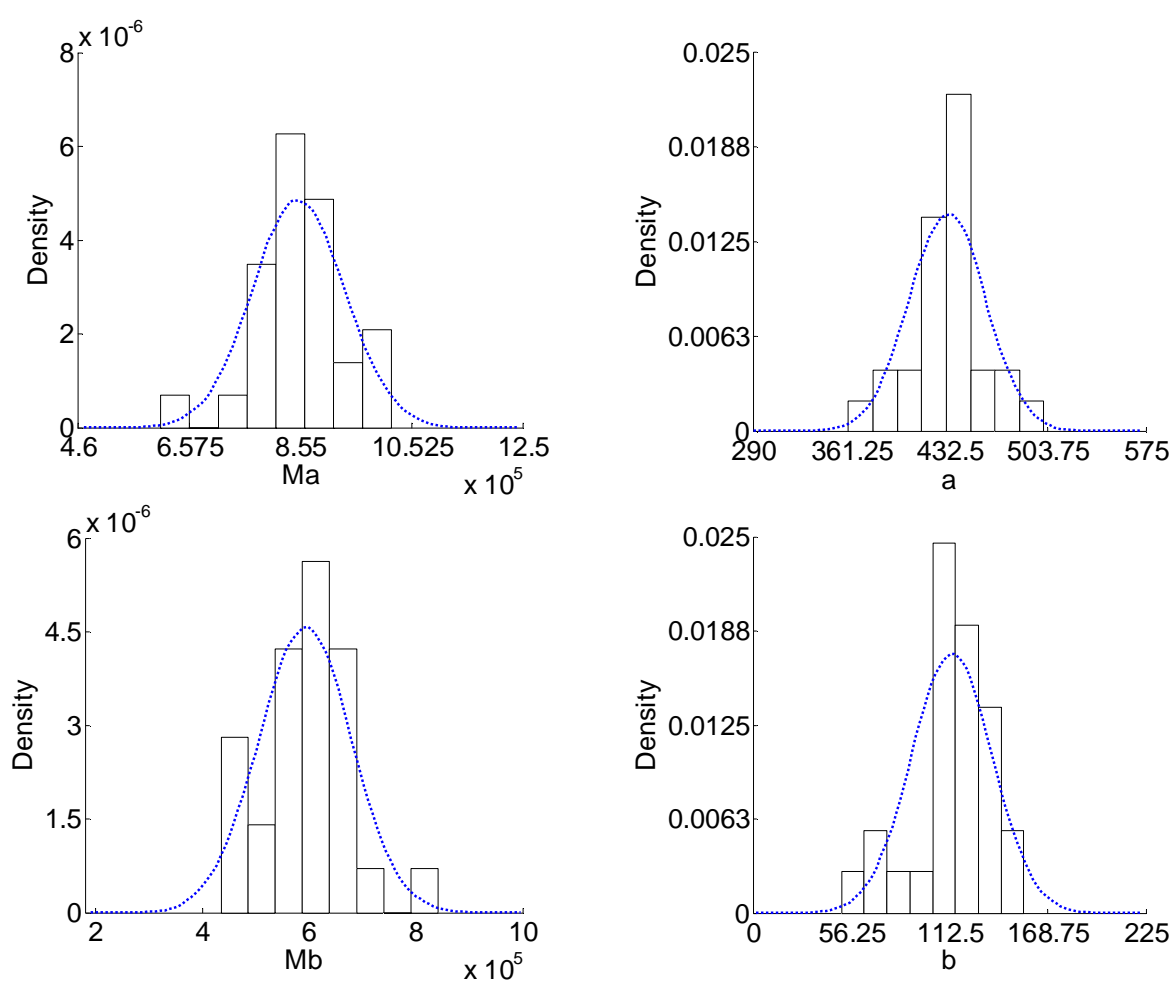

Fig. 6.Histograms and probability densities (Gaussians) of the $\mathrm{B}(\mathrm{H})$ magnetic behavior law parameters $\left(M_{a}, M_{b}, a, b\right)$
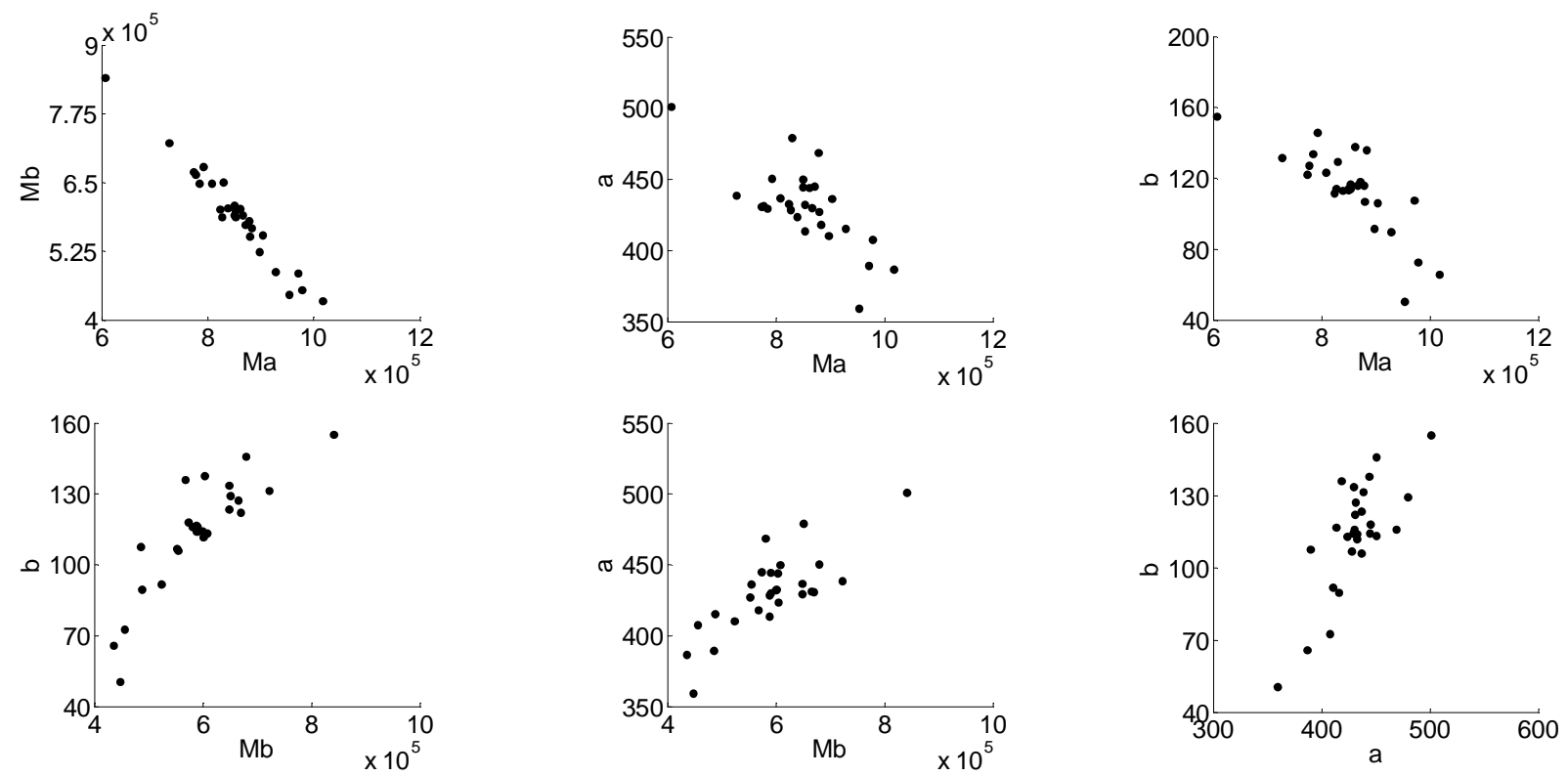

Fig. 7. Scatter plots of the $\mathrm{B}(\mathrm{H})$ magnetic behavior law parameters $\left(M_{a}, M_{b}, a, b\right)$ : linear correlation between parameters 

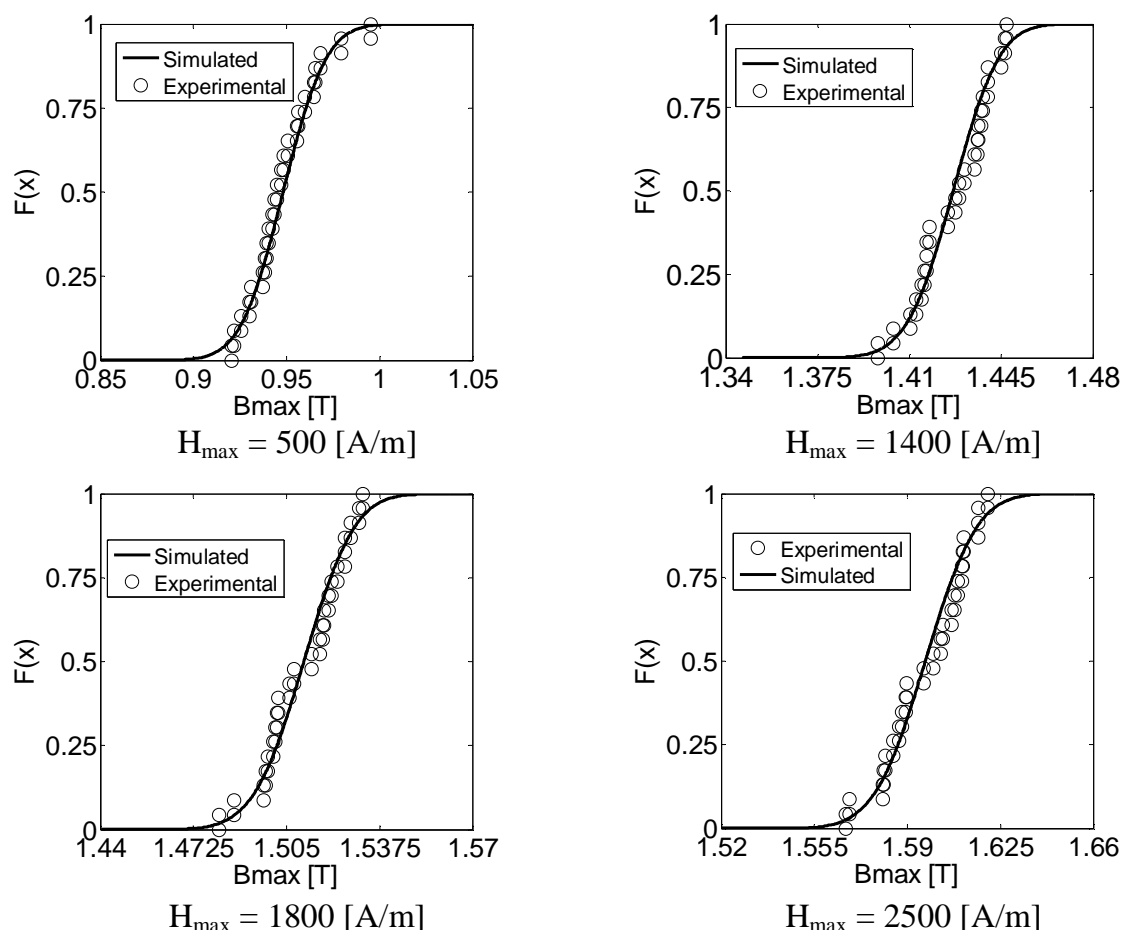

Fig. 8.Experimental and predicted $\mathrm{CDF}$ of $\mathrm{B}_{\max }$ for four levels of $\mathrm{H}_{\max }$ at $50 \mathrm{~Hz}$ for the $\mathrm{B}(\mathrm{H})$ model simulation: adequacy between experiment and simulation

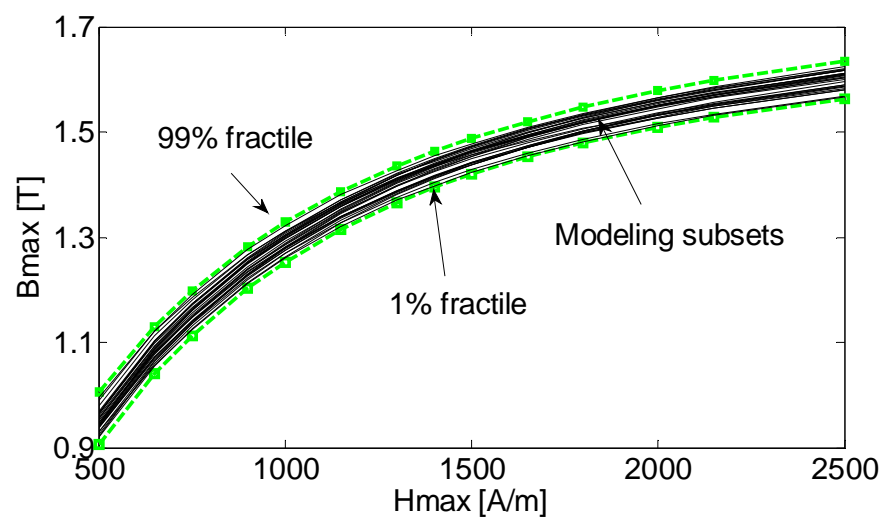

Fig. 9. $98 \% \mathrm{CI}$ of $\mathrm{B}_{\max }\left(\mathrm{H}_{\max }\right)$ curves identified with the model and the modeling subsets: comparison of the CI and experimental trajectories (23 experimental trajectories)

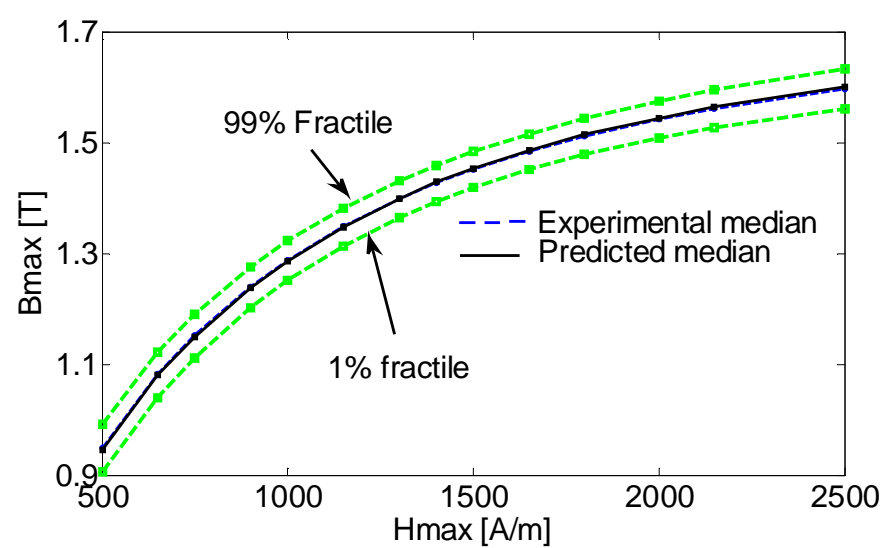

Fig. 10. Experimental and predicted $\mathrm{B}_{\max }\left(\mathrm{H}_{\max }\right)$ median curves: comparison between experiment and simulation 


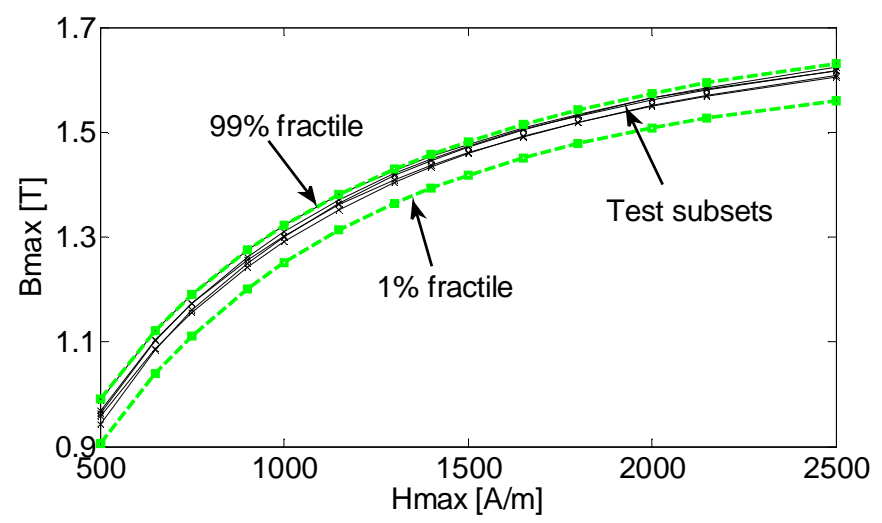

Fig. 11. 98\% CI for the $\mathrm{B}_{\max }\left(\mathrm{H}_{\max }\right)$ curves and test subset (5 experimental trajectories) that lies within the $\mathrm{CI}$

\section{INVERSE BEHAVIOR LAW MODEL SIMULATION}

In the case of vector potential formulation in finite element analysis, one needs to define the magnetic flux density B as the input variable. Then, by considering the inverse model $\mathrm{H}(\mathrm{B})$, it is shown in figure 3 that the variability of $\mathrm{H}_{\max }$ becomes much higher when the $\mathrm{B}_{\max }$ level increases, with a coefficient of variation between $3.72 \%$ and $5.77 \%$ (compared to $2 \%$ for the direct $\mathrm{B}(\mathrm{H})$ model).

In this case, the MG distribution model of the parameters vector previously identified can be used directly to simulate the variability of $\mathrm{H}_{\max }$, for the studied stator samples, when considering the magnetic flux density $\mathrm{B}_{\max }$ as the input. To this end, the Newton-Raphson algorithm is implemented as follows:

1-Set the maximum flux density level $\mathrm{B}_{\max }$

2-Calculate the derivative $\left(\mathrm{B}_{\max }\right)$ ' given by (7), with respect to $\mathrm{H}_{\max }$

3-Generate the vector $\boldsymbol{X}=\left\{\boldsymbol{M}_{\boldsymbol{a}}, \boldsymbol{M}_{\boldsymbol{b}}, \boldsymbol{a}, \boldsymbol{b}\right\}$, according to MG distribution, where $\mathbf{X}$ is of size ( $\mathrm{n} \times 4)$

4-Set $\mathrm{H}_{\max }(\mathrm{k})$ the initial value of Newton-Raphson algorithm

5-Set $\mathbf{X}=\mathbf{X}(\mathrm{j}, 4)$
6-Compute: $H_{\text {max }}(k+1)=H_{\text {max }}(k)+\frac{B_{\text {max }}\left(H_{\text {max }}(k)\right)}{B_{\text {max }}^{\prime}\left(H_{\text {max }}(k)\right)}$

7-If $\left\|H_{\text {max }}(k+1)-H_{\text {max }}(k)\right\|<\varepsilon$, set $j=j+1$, otherwise redefine the initial value as $H_{\max }(k+1)$ in step 4

8-Repeat steps 4-7 until $j=n$

9-Repeat steps 1-8 for all $B_{\max }$ levels.

One million realizations of the vector of parameters are performed for $\mathbf{X}$, and the $\mathrm{CDF}$ of $\mathrm{H}_{\max }$ for all $\mathrm{B}_{\max }$ levels is identified. These are compared with the experimental ones as illustrated in figure 12, for 4 levels of $\mathrm{B}_{\max }$. Then, the KS test at a risk of $5 \%$ for all $\mathrm{B}_{\max }$ levels is applied, and returned pvalues between 0.1 and 0.8 . These values allow not rejecting the null hypothesis that they are issued from the same distribution, at a risk of 5\%. Moreover, the $98 \% \mathrm{CI}$ of $\mathrm{H}_{\max }$ is identified and compared to experimental trajectories in figure 13. According to this figure, all the experimental trajectories $\mathrm{H}_{\max }\left(\mathrm{B}_{\max }\right)$ lie within the identified CI. Finally, predicted and experimental medians are compared in figure 14. As it is shown in this figure, they are close: the maximum disparity is $3.03 \%$ for the higher level that remains an acceptable error.

As for the direct model $\mathrm{B}(\mathrm{H})$, the inverse stochastic model can be used directly as input for stochastic finite elements analysis in vector potential formulation [13, 14]. 

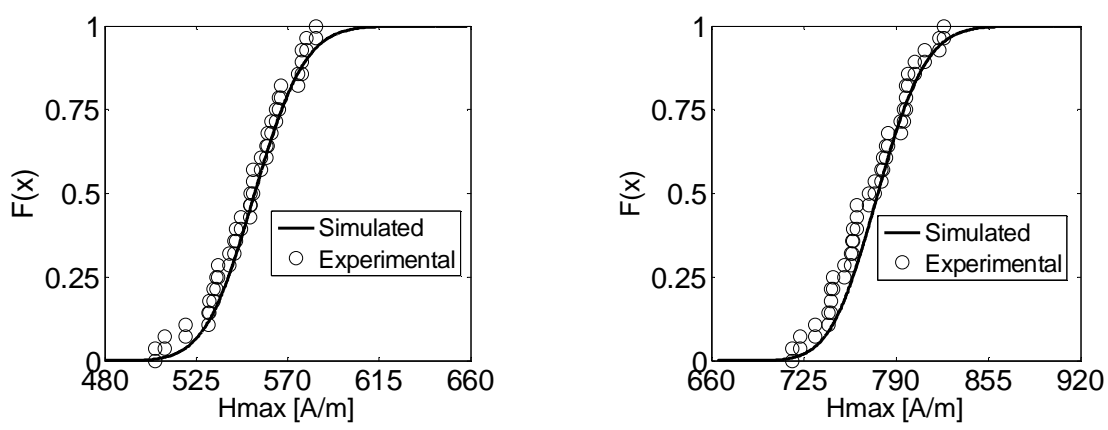

$\mathrm{B}_{\max }=1[\mathrm{~T}]$

$\mathrm{B}_{\max }=1.17[\mathrm{~T}]$
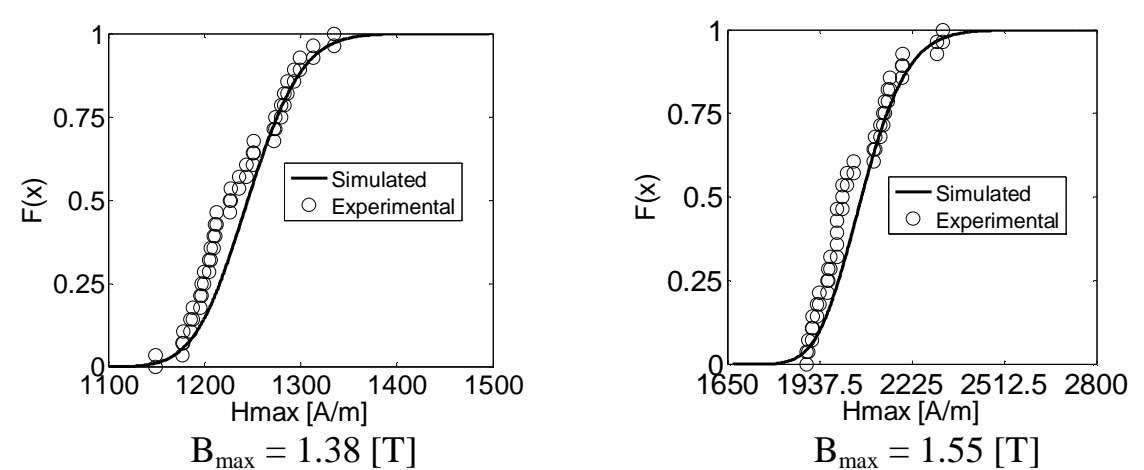

Fig. 12. Experimental and predicted $\mathrm{CDF}$ of $\mathrm{H}_{\max }$ for four levels of $\mathrm{B}_{\max }$ for the inverse behavior law: adequacy between the experimental data and the simulation

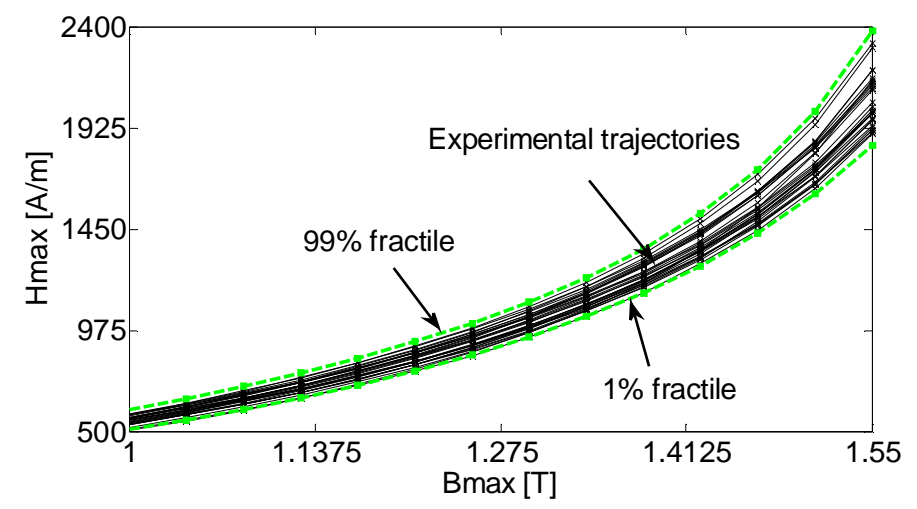

Fig. 13. 98\% CI $\mathrm{H}_{\max }\left(\mathrm{B}_{\max }\right)$ curves and experimental trajectories for the inverse behavior law: comparison of the CI and experimental trajectories 


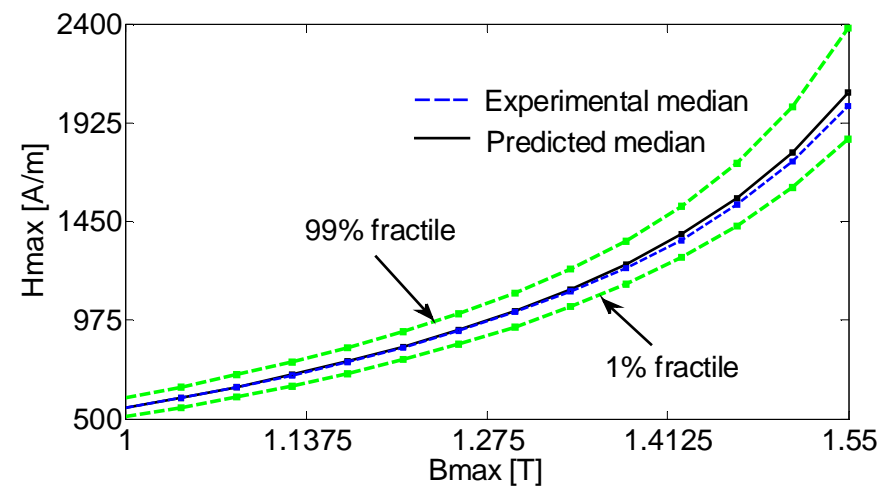

Fig. 14. Experimental and predicted $H_{\max }\left(B_{\max }\right)$ median curves for the inverse behaviour law: comparison show good agreement.

\section{StOchastiC MODELING OF IRON LOSSES}

\section{A. Iron losses separation approach}

Iron loss prediction in ferromagnetic steel has been subjected to many studies. According to the phenomenological principle proposed by Bertotti [24], the so-called loss separation approach, the average power loss per unit volume $\mathrm{P}_{\mathrm{s}}$ for electrical steel is decomposed in static and dynamic contributions. This latter contribution is composed of the classical and excess losses, which are separately investigated,

$$
P_{s}=P_{\text {stat }}+P_{\text {class }}+P_{\text {exc }}
$$

where $P_{\text {stat }}$ are the quasi-static hysteresis losses, $P_{\text {class }}$ are the classical losses (macroscopic eddy currents) and $P_{e x c}$ are the excess losses (dynamic behavior of the magnetic domains) [27]. Analytical models have been proposed to investigate these components that require the identification of parameters. These are dependant on the chemical and physical characteristics of the considered material [25-28]. Therefore, for sinusoidal supply, the hysteresis losses can be approximated by the following well known equation proposed by Steinmetz [29], where $B_{\max }$ is the peak value of the flux density, $f$ the frequency and $\alpha$ the Steinmetz coefficient.

$$
P_{h y s t}=k_{h} f B_{\max }^{\alpha} .
$$

The classical losses can be computed using (16), assuming the skin effect to be negligible, and the excess losses are calculated with expression (17).

$$
\begin{gathered}
P_{\text {class }}=k_{e}\left(f B_{\text {max }}\right)^{2} \\
P_{\text {exc }}=k_{\text {exc }}\left(f B_{\text {max }}\right)^{3 / 2}
\end{gathered}
$$

In order to identify the parameters $\left(k_{h}, \alpha, k_{e}, k_{e x c}\right)$, the iron losses have to be measured for several magnetic flux densities and frequencies, and used to minimize the following function,

$$
\sum_{i=1}^{n}\left(P_{\text {meas }}-P^{*}\right)^{2}
$$

where $P_{\text {meas }}$ is the measured iron losses, $n$ the number of experimental data and $P^{*}$ the predicted iron losses.

To develop stochastic model of iron losses of the considered samples, the same approach as for the magnetic behavior law is used.

\section{B. Parameters identification-variability}

The characterization is achieved for 5 levels of $B_{\max }$ (sinusoidal induction) and 6 levels of frequency (5 to $200 \mathrm{~Hz}$ ). As for the $\mathrm{B}(\mathrm{H})$ stochastic modeling approach, the experimental data are split in two sets: a modeling subset used to develop the stochastic model and a test subset to validate the model. To identify the quasi-static loss parameters $k_{h}$ and $\alpha$, it is assumed that only the quasi-static behavior is involved at $5 \mathrm{~Hz}$. Then, coefficients $k_{h}, \alpha, k_{e}$ and $k_{e x c}$ are identified for each stator sample (modeling subset), for the whole frequencies and $\mathrm{B}_{\max }$ levels. Histograms and scatter plots of the identified parameters are presented in figures 15 and 16 respectively. The linear correlation matrix of the 4 parameters is given in table 5 .

TABLE V

LINEAR CORRELATION OF IRON LOSSES IDENTIFIED PARAMETERS

\begin{tabular}{ccccc}
\hline \hline & $k_{h}$ & $\alpha$ & $k_{e}$ & $k_{\text {exc }}$ \\
\hline$k_{h}$ & 1 & 0.35 & -0.17 & -0.04 \\
$\alpha$ & 0.35 & 1 & -0.1 & 0.26 \\
$k_{e}$ & -0.17 & -0.1 & 1 & -0.64 \\
$k_{e x c}$ & -0.04 & 0.26 & -0.64 & 1 \\
\hline \hline
\end{tabular}

From this table, it can be observed that the dynamic loss parameters $k_{e}$ and $k_{e x c}$ are correlated. A MG distribution is then chosen to take into account the variability and correlation of the four parameters. With this assumption, correlations between the four parameters, even if not significant, are taken into account. 


\section{Model validation}

1) Goodness of fit statistic

A Monte Carlo simulation for one million realizations is performed, for each $\mathrm{B}_{\max }$ level at $50 \mathrm{~Hz}$, and the CDF of the total iron losses $\mathrm{P}_{\mathrm{t}}$ is identified for each $\mathrm{B}_{\max }$ level. $\mathrm{A}$ comparison with the experimental $\mathrm{CDF}$ is illustrated in figure 17 for two levels of $\mathrm{B}_{\max }$.

It can be observed that the experimental CDF are well approximated by the simulated ones. Moreover, the two samples Kolmogorov Smirnov (KS) test is then used to test the null hypothesis $\mathrm{H}_{0}$ that they are issued from the same continuous distribution, at a risk of 5\%, against the hypothesis $\mathrm{H}_{1}$ that they are coming from different probability distributions. For the whole level of $\mathrm{B}_{\max }$, the $p$ values are between 0.09 and 0.44 for $50 \mathrm{~Hz}$. These values allow not rejecting the null hypothesis, for all $\mathrm{B}_{\max }$ level at a risk of $5 \%$. This validates the simulated $\mathrm{CDF}$ with the defined risk criteria.

\section{2) Confidence interval}

The $98 \% \mathrm{CI}$ is also identified for all levels of $\mathrm{B}_{\max }$. The modeling subsets are compared with the identified CI in figure 18. According to this figure, the modeling subsets lie within the predicted $98 \%$ CI. The predicted and experimental medians are also compared in figure 19, and the maximum disparity is $1.2 \%$, which is acceptable. Finally, the test subsets are compared with the $98 \% \mathrm{CI}$ in figure 20 . It is observed that the test subset lies within the identified CI. All these criteria then allow validating the stochastic model of the iron losses. According to all the criteria listed above, the developed stochastic model is representative of the iron losses variability among the samples.

Note that the developed model can be used to estimate a CI for the iron losses at a frequency level of interest, providing the physical assumption are still verified (greater skin depth with regard to the lamination thickness). As illustration example, figure 21 shows the experimental iron losses curves for $100 \mathrm{~Hz}$ that lie within the $98 \% \mathrm{CI}$ identified from the model.
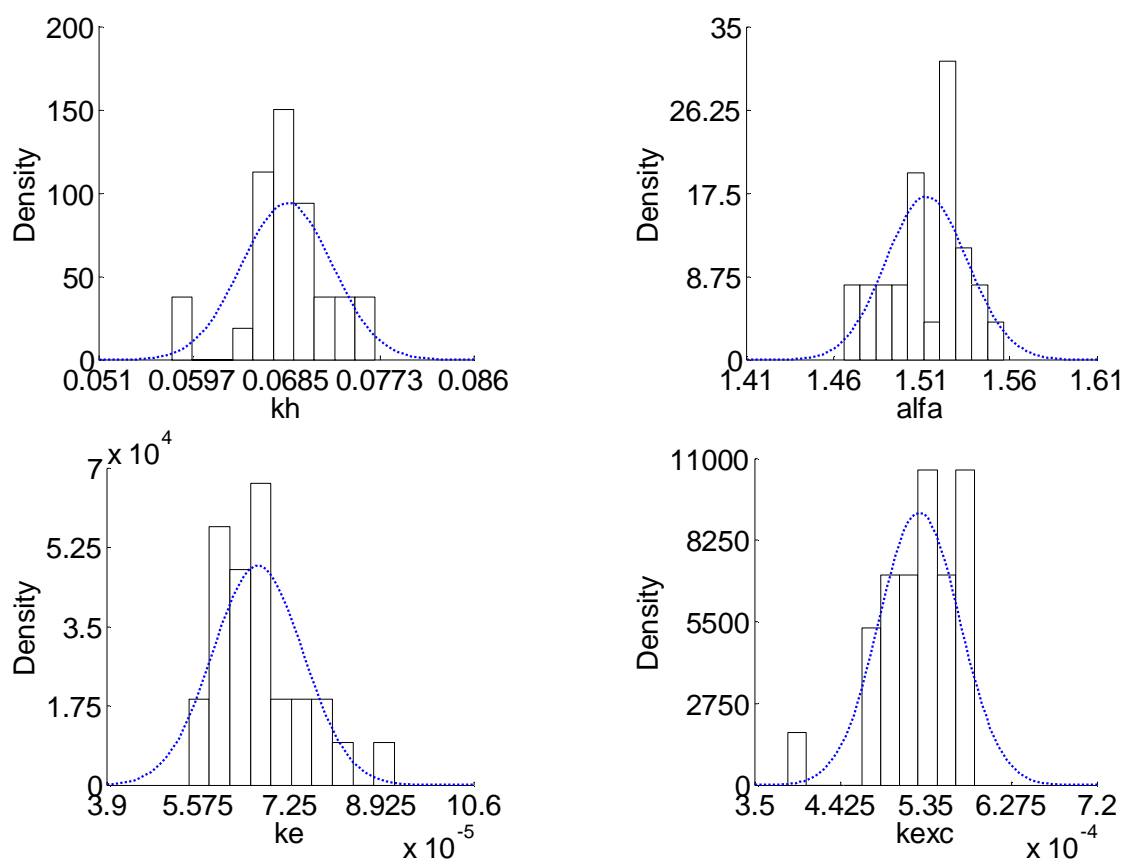

Fig. 15.Histograms and probability densities (Gaussians) of iron losses parameters $\left(k_{h}, \alpha, k_{e}, k_{e x c}\right)$ 

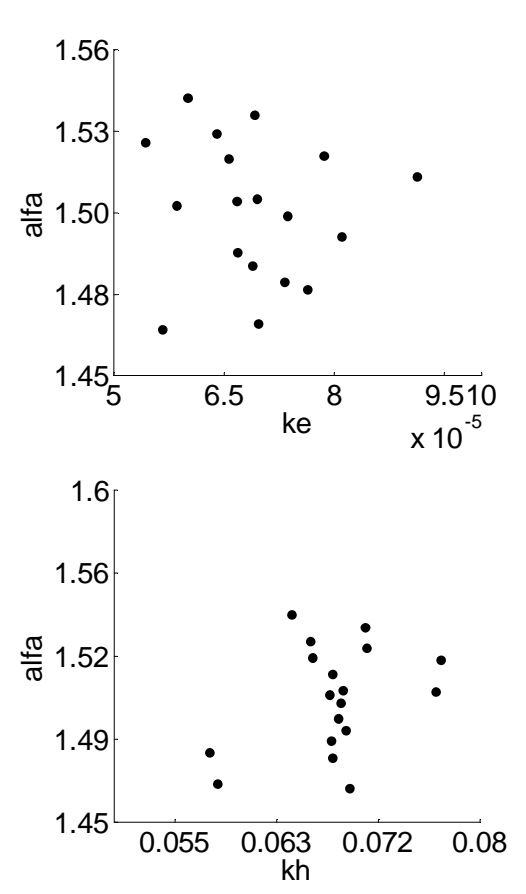
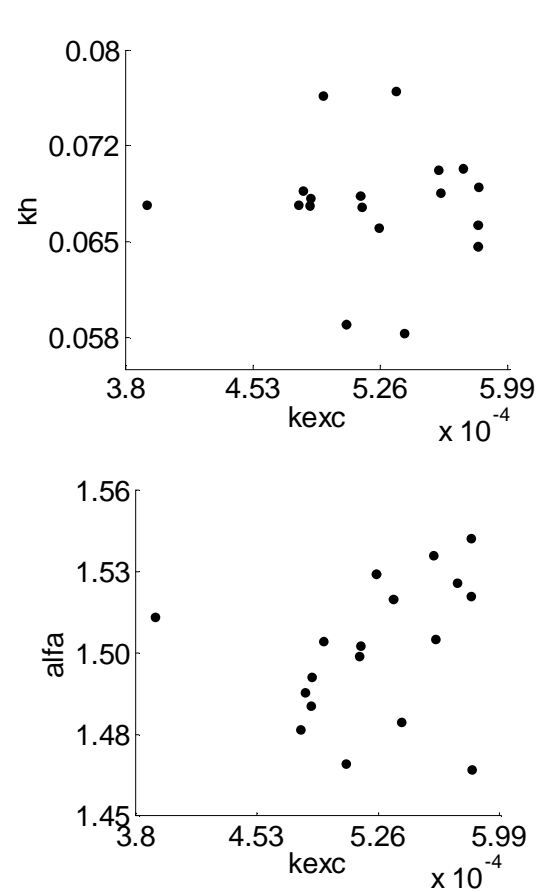
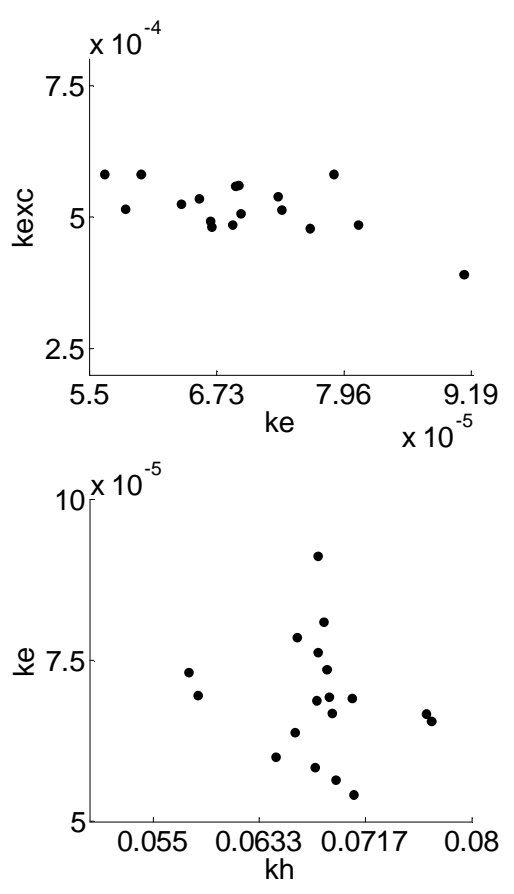

Fig. 16. Scatter plots of iron losses parameters $\left(k_{h}, \alpha, k_{e}, k_{\text {exc }}\right)$ : analyzes of the linear correlation
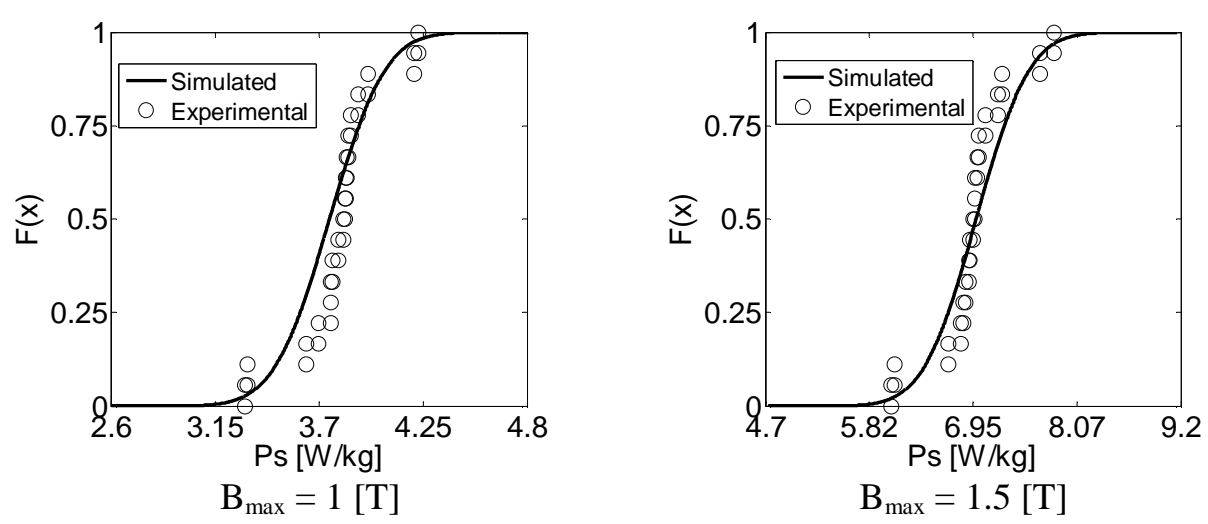

Fig. 17. Experimental and predicted CDF of iron losses for two levels of $\mathrm{B}_{\max }$ at $50 \mathrm{~Hz}$ : adequacy between the simulation and experimental data

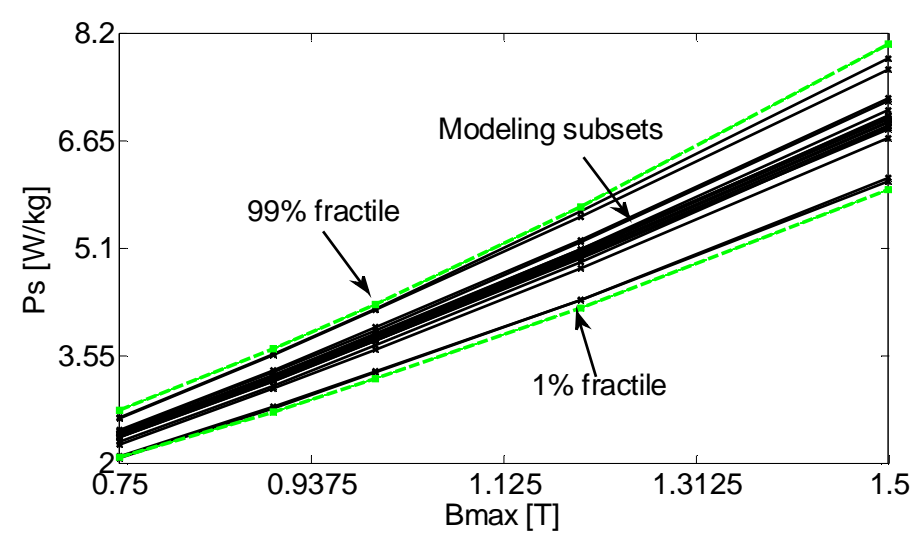

Fig. $18.98 \% \mathrm{CI}$ of iron losses curves and modeling subsets at $50 \mathrm{~Hz}$ : comparison of the $\mathrm{CI}$ and experimental trajectories (23 experimental trajectories) 


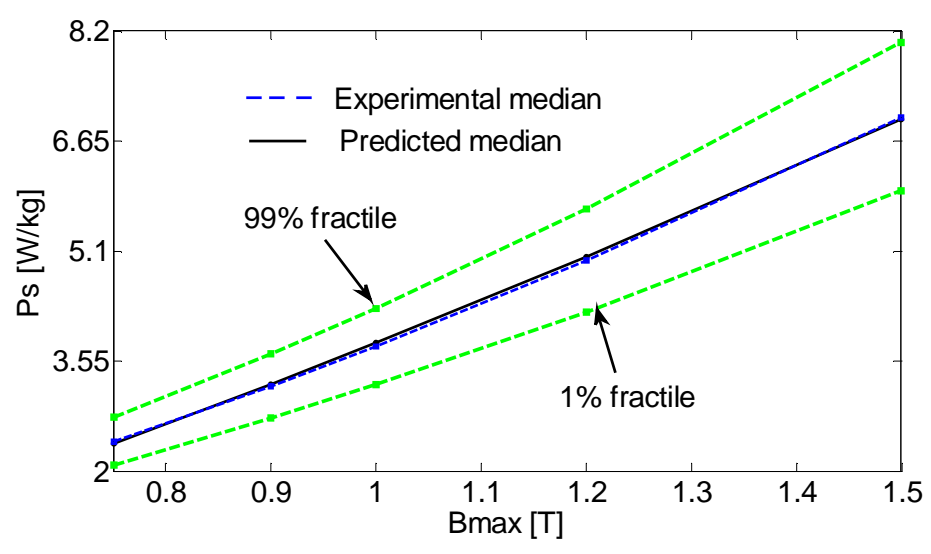

Fig. 19. Experimental and predicted iron losses median curves at 50Hz: comparison

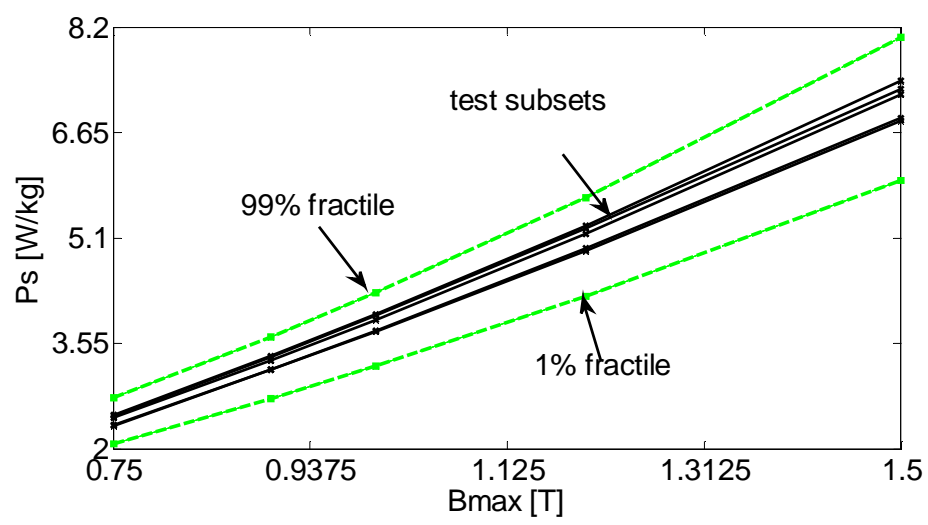

Fig. 20. 98\% CI of iron losses curves and test subsets at 50Hz: comparison of the $\mathrm{CI}$ and test subsets (5 trajectories)

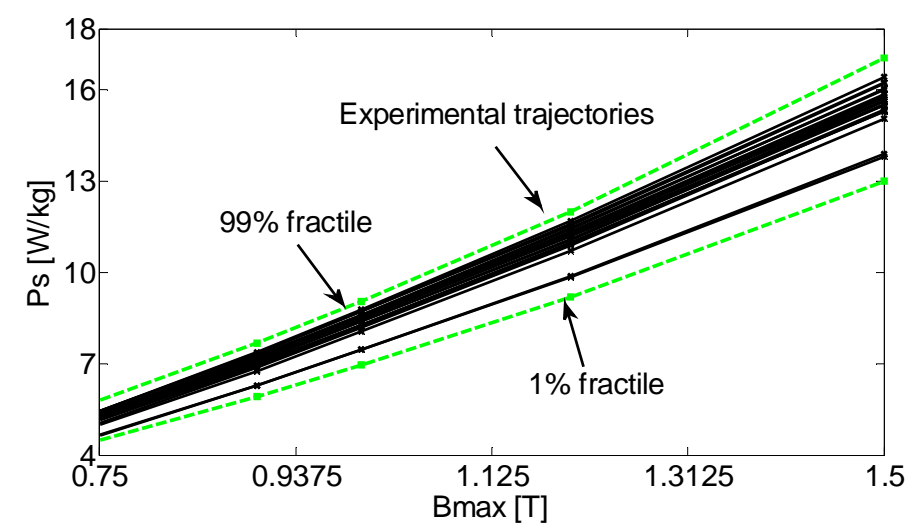

Fig. 21. $98 \% \mathrm{CI}$ of iron losses curves and experimental trajectories at 100Hz: comparison of the $\mathrm{CI}$ and trajectories

\section{CONCLUSION}

Several works have been focused on the quantification of the influence of the manufacturing process (cutting and assembly process) on the magnetic properties of magnetic material, such as the magnetic behavior law and the iron losses. However, models that take into account these influences and their variabilities for direct use in the design of electrotechnical devices are still relevant. This paper proposed an approach to develop stochastic models that take into account the stochastic aspect for both the magnetic behavior law and iron losses using experimental data. The approach was applied in the case of slinky stator samples that present significant variability.

The deterministic modified Brillouin model was chosen to approximate the magnetic anhysteretic curve of the samples, using the coefficient of efficiency criteria and a 3-fold cross validation technique. On the other hand, the iron loss model based on the three loss contributions is used to approximate the iron losses of these samples. The used approaches for stochastic modeling are similar for both the magnetic behavior law and iron losses. The probability distributions of the model parameters, both for magnetic behavior law and iron losses, 
were assumed to verify a Multivariate Gaussian distribution. The chosen probabilistic models of the identified parameters have been validated by comparing simulated and experimental $\mathrm{CDF}$, and by implementing the two samples KS test at a risk of $5 \%$. The developed stochastic model for magnetic behavior law allows one to implement inverse simulation, in the case of the vector potential formulation in finite element analysis. Moreover, the stochastic iron losses model may be used to simulate the variability of the iron losses for frequencies levels, other than $50 \mathrm{~Hz}$, providing the physical assumptions of the loss model are still verified.

More generally, the proposed methodology can be applied to deal with the variability of magnetic core parts in electrical devices. In fact, this methodology used to develop the stochastic behavior law and iron losses models is independent from the considered system or magnetic material. These models can be then used as input for a stochastic finite element simulation to take into account the uncertainties in electrical machines [13-14] for a design or existing device modeling purpose.

\section{APPENDIX}

\section{APPENDIX A: GENERATING MG DISTRIBUTION}

Assume that $\mathbf{X}$ is a p-dimensional column vector, $\boldsymbol{\mu}$ a vector (vector of the mean), and $\sum$ a positive definite symmetric matrix (covariance matrix of $\mathbf{X}$ ). The probability distribution function for the MGD is defined by

$$
f(x)=\frac{1}{\sqrt{(2 \pi)^{\frac{p}{2}} \operatorname{det}(\Sigma)}} \exp \left(-\frac{1}{2}(x-\mu)^{T} \Sigma^{-1}(x-\mu)\right) .
$$

The following algorithm can been used to draw values from the distribution:

a. find any real lower triangular matrix $A$ such that $A A^{\mathrm{T}}=\sum$. When $\sum$ is a definite positive matrix, the Cholesky decomposition can be used for this end,

b. generate a vector $Z=\left(z_{1, \ldots}, z_{p}\right)^{T}$ whose components are $\mathrm{N}$ independent standard normal variates,

c. finally, the desired distribution due to the affine transformation property can be simulated with $\mu+A Z$.

\section{APPENDIX B: KOLMOGOROV SMIRNOV HYPOTHESIS TESTING}

Statistical hypothesis testing postulates a null hypothesis $\mathrm{H}_{0}$ which requires testing, and a complementary hypothesis $\mathrm{H}_{1}$. The objective is then to reject or not to reject the null hypothesis $\mathrm{H}_{0}$, with which is associated a risk $\alpha$, from a statistic calculated from observations. Two samples Kolmogorov Smirnov (KS) statistical test is by definition a non-parametric test for the equality of two continuous probability distributions, and aims to quantify the distance between the empirical distribution functions of these samples. Mathematically, this distance is defined by
$D_{n_{1} n_{2}}=\sqrt{\frac{n_{1} n_{2}}{n_{l}+n_{2}}} \sup _{x \in R}\left\{\left|\hat{F}_{n_{1}}^{X}(x)-\hat{F}_{n_{2}}^{Y}(x)\right|\right\}$

where $n_{1}$ (respectively $n_{2}$ ) is the size of the sample and $\hat{\mathrm{F}}_{\mathrm{n}}^{\mathrm{X}}(\mathrm{x})$ (respectively $\hat{\mathrm{F}}_{\mathrm{n}}^{\mathrm{y}}(\mathrm{x})$ ) the empirical distribution function. The null hypothesis is then rejected at a level $\alpha$ if $D_{n_{1} n_{2}} \geq K_{\alpha}\left(n_{1}, n_{2}\right)$ where $K_{\alpha}\left(n_{1}, n_{2}\right)$ is obtained from the table of critical values of KS test.

\section{REFERENCES}

[1] E.Dlala, A.Belahcen, A.Arkkio, "On the Importance of Incorporating Iron Losses in the Magnetic Field Solution of Electrical Machines", IEEE Trans on Mag. Vol. 46, N8, pp 3101-3104, 2010.

[2] K.Yamazaki, N.Fukushima, «Iron-Loss Modeling for Rotating Machines: Comparison Between Bertotti's Three-Term Expression and 3-D Eddy-Current Analysis", IEEE Trans on Mag. Vol. 46, $\mathrm{N}^{\circ} 8$, pp 3121-3124, 2010.

[3] C. Simão, N. Sadowski, N. J. Batistela, J. P. A. Bastos, "Evaluation of Hysteresis Losses in Iron Sheets Under DC-biased Inductions", IEEE Trans on Mag. Vol. 45, N³, pp 1158-1161, 2009.

[4] J.Korecki, A.Benabou, Y.Le Menach, F.Piriou, J.P.Ducreux, "Hysteresis Phenomenon Implementation in FIT: Validation With Measurements", IEEE Trans on Mag. Vol. 46, $\mathrm{N}^{\circ} 8$, pp 3286-3289, 2010.

[5] Y.Kai, Y.Tsuchida, T.Todaka,M.Enokizono, "Influence of Stress on Vector Magnetic Property Under Alternating Magnetic Flux Conditions », IEEE Trans on Mag. Vol. 47, N 10 , pp 4344-4347, 2011.

[6] L. Mierczak, D. C. Jiles, G. Fantoni, "A New Method for Evaluation of Mechanical Stress Using the Reciprocal Amplitude of Magnetic Barkhausen Noise", IEEE Trans on Mag. Vol. 47, N² , pp 459-465, 2011.

[7] F. Libert, J. Soulard, "Manufacturing Methods of Stator Cores with Concentrated Windings", Proceedings of IET International Conference on Power Electronics, Machines and Drives PEMD, pp. 676-680, 2006.

[8] Y. Liu, S.Mahadevan, "Stochastic fatigue damage modeling under variable amplitude loading", International Journal of Fatigue, pp 11491161, 2007.

[9] W.F. Wu, C.C. Ni, "A study of stochastic fatigue crack growth modelling through experimental data", Probabilistic Engineering Mechanics 18, pp 107-118, 2003.

[10] C. Soize, E. Capiez-Lernout, J.-F. Durand, C. Fernandez, L. Gagliardini, "Probabilistic model identification of uncertainties in computational models for dynamical systems and experimental validation", Comput. Methods Appl. Mech. Engrg. 198, pp 150-163, 2008.

[11] B.Sudret, "Uncertainty propagation and sensitivity analysis in mechanical models, contributions to structural reliability and stochastic spectral method" - HDR Université Blaise Pascal Clermont II, 2007.

[12] Kotulski, Z. A., "On efficiency of identification of a stochastic crack propagation model based on Virkler experimental data" Archives on Mechanics, pp 829 - 847, 1998.

[13] R. Gaignaire, S. Clénet, O. Moreau, B. Sudret, "Current Calculation in Electrokinetics using a Spectral Stochastic Finite Element Method", IEEE Trans. Mag. Vol. 44, N.6, pp.754-757, 2008.

[14] R. Gaignaire, S. Clenet, B. Sudret, O. Moreau, "3D Spectral Stochastic Finite Element Method in Electromagnetism”, IEEE Trans on Mag. Vol. 43, N4, pp $1209-1212,2007$.

[15] R. Ramarotafika, A. Benabou, S. Clénet, "Experimental characterization of the iron loss variability in stators of electrical machines", IEEE Trans on Mag. Vol. 48, N4 , pp 1629 - 1632, 2012.

[16] F C. Trutt, E.A. Erdélyi, R. E. Hopkins, "Representation of the Magnetization characteristic of DC Machines for Computer Use", IEEE transactions on Power Apparatus and Systems, Vol. PAS-87 No. 3, pp 665-669, 1968.

[17] D.C Jiles and D.L Atherton, "Theory of ferromagnetic hysteresis", Journal of Magnetism and Magnetic Materials, Vol. 61, pp. 48-60, 1986.

[18] Z.Wlodarski, "Analytical description of magnetization curves", Physica B 373, pp 323-327, 2006.

[19] R. Kohavi, "A Study of Cross-Validation and Bootstrap for Accuracy Estimation and Model Selection", Proceedings of the 14th international joint conference on Artificial intelligence, Vol 2, pp. 1137-1143, 1995. 
[20] P Refaeilzadeh, L. Tang, H Liu, "Cross-Validation", Arizona State University, 2008.

[21] S.Arlot, "A survey of cross-validation procedures for model selection", Statistics Surveys, Vol. 4, pp 40-79, 2010.

[22] B.Efron, G.Gong, "A Leisurely look at the bootstrap, the jackknife and cross validation", The American Statistician, Vol. 37, pp 36-48 $\mathrm{N}^{\mathrm{o}} 1$, 1983.

[23] L. Mehrez1, A. Doostan, D. Moens1, D. Vandepitte, “A Validation Study of a Stochastic Representation of Composite Material Properties from Limited Experimental Data", Proceedings of ISMA 2010-USD 2010, K.U.Leuven, Department Mechanical Engineering, 2010.

[24] G.Bertotti, "General properties of power losses in soft ferromagnetic materials”, IEEE Trans. Mag. Vol. 24, N¹, pp. 621-630, 1998.

[25] A.Boglietti, A.Cavagnino, M.Lazzari, and M.Pastorelli, "Predicting Iron Losses in Soft Magnetic Materials With Arbitrary Voltage Supply: An Engineering Approach”, IEEE Trans. Mag. Vol.39, N², pp 981-989, 2003.

[26] M. Amar and R. Kaczmarek, "A general formula for prediction of iron losses under nonsinusoidal voltage waveform”, IEEE Trans. Mag. Vol. 31, N5, pp. 2504-2509, 1995.

[27] A. Boglietti, A. Cavagnino, M. Lazzari, M. Pastorelli, "Two simplified methods for the iron losses Prediction in soft magnetic materials supplied by PWM Inverter", Proceedings of Electric Machines and Drives Conference, IEMDC, pp.391-395, 2001.

[28] A. Boglietti, A. Cavagnino, "Iron loss prediction with PWM supply: An overview of proposed methods from an engineering application point of view", Proceedings of Industry Applications Conference, 42nd IAS Annual Meeting, pp. 81-88, 2007.

[29] C. P.Steinmetz, "On the law of hysteresis", American Institute of Electrical Engineers Transactions, Vol.9, pp 3-64, 1982.

[30] W. M. Arshad, T. Ryckebush, F. Magnussen, H. Lendenmann, B.Eriksson, J. Soulard, and B. Malmross, "Incorporating lamination processing and component manufacturing in electrical machine design tools", in Proc. of Industry Applications Conf., 42nd IAS Annual Meeting, pp. 94-102, 2007.

[31] A. Schoppa, J. Schneider, and C. D. Wuppermann, "Influence of the manufacturing process on the magnetic properties of non-oriented electrical steels," Journal of Magnetism and Magnetic Materials, Vol. 215-216, pp. 74-78, 2000.

[32] A. Kedous-Lebouc, B. Cornut, J. C. Perrier, P. Manfé, and T. Chevalier, "Punching influence on magnetic properties of the stator teeth of an induction motor," Journal of Magnetism and Magnetic Materials, Vol. 254-255, pp. 124-126, 2003.

[33] A. Boglietti, A. Cavagnino, M. Lazzari, and M. Pastorelli, "Effects of punch process on the magnetic and energetic properties of soft magnetic material," in Proc. of Electric Machines and Drives Conf., IEMDC, pp. 396-399, 2001. 